\title{
FUNGSI NASKAH PRUDAK SINA DALAM KEHIDUPAN MASYARAKAT SASAK DALAM PERSPEKTIF NILAI AGAMA DAN PENDIDIKAN
}

\author{
Muhammad Sukri \\ FKIP Universitas Mataram Gedung A Lantai I \\ Jalan Majapahit No. 62 Mataram \\ Email: sukrimuhammad75@gmail.com
}

\begin{abstract}
Abstrak:
Prudak Sina adalah sebuah lakon/tokoh sebuah cerita yang arif dan bijaksana, dalam pikiran, perkataan dan perbuatannya. Ia adalah Lelananging Jagad yang dicintai oleh lelaki di dunia dan sebagai tempat berlindung bagi wanita. Naskah ini mengandung makna yang dalam dilihat dari filsafat ajaran Islam. Naskah Prudak Sina dalam dialognya dengan isteri mengandung nilai dan fungsi yang merupakan corak khas masyarakat Sasak dulu, dan seharusnya menjadi dasar dan panutan bagi setiap suami dalam menggauli isterinya. Penelitian qualitatif ini melibatkan beberapa narasumber baik penikmat, pujangga, pemaos maupun penyukum yang cukup kredibel memahami dan mengembangkan naskah lontar. Data yang diperoleh dianalisis dengan menggunakan analisis deskriptif dalam bentuk ekstraksi. Hasil penelitian menyimpulkan bahwa nilai yang terkandung dalam naskah yaitu, nilai-nilai religiusitas dan pendidikan. Ki Prudak Sina, penulis sekaligus tokoh kisah berupaya mensyiarkan Islam melalui tembang-tembang seperti Prudak Sina. Berdasarkan kesimpulan, sarannya adalah agar mempelajari, mengambil hikmat dan contoh-contoh dari keteladanan yang ditonjolkan oleh tokoh khususnya dalam menggauli isteri.
\end{abstract}

\begin{abstract}
Abstrak:
Prudak Sina is a character in wise and prudent story, either in thought, word and in deeds. He is Lelananging Jagad that should be loved by the men on earth and as a shelter for women. It contains very deep meaning in terms of the philosophy of the teachings of Islam. Prudak Sina's script in dialogue with his wife contains a number of values and functions which is a typical pattern of Sasak people in the past, noble values that should be the basis and model for every man in thinking, saying and acting to his wife. This qualitative study involved some good resource such as connoisseur, poet, staff supporter, and script reader who are credible enough to understand and sing papyrus manuscript. The data obtained then analyzed using descriptive analysis in the form of extraction. The results of this study are religiosity and education. Ki Prudak Sina, the author as well as the character of this story, preached Islam through songs such Prudak Sina song. Based on these conclusions, the author suggests to take wisdom and examples of exemplary character highlighted by the author especially in intercourse with wife as a companion of life.
\end{abstract}

\section{Kata Kunci:}

Naskah Prudak Sina, Nilai dan Fungsi, Kehidupan Seni dan Budaya Sasak

HAMPIR di setiap daerah muncul nama-nama tokoh agama yang sangat kuat pengaruhnya, agung namanya, dan bahkan dikeramatkan kuburannya. Nama-nama besar itu ada yang tertulis dalam buku sejarah namun kini mulai lepas dari ingatan 
masyarakat. Padahal gaung dan sepak terjang mereka saat itu, meluas, merasuk di setiap hati masyarakat pada zamannya. Mereka terkenal bukan hanya karena ajaranajaran dan keteladanan yang telah mereka tunjukkan, akan tetapi juga oleh tulisantulisan berupa kitab, naskah cerita, mitos, atau takepan yang biasanya ditulis di atas pelepah lontar. ${ }^{1}$

Prudak Sina adalah salah satu judul takepan lontar yang tersimpan dalam budaya Sasak. Prudak Sina adalah nama seorang Pendita yang Aji Duta Semu, dan sekaligus tokoh pencerita dalam naskah ini, berdialog dengan isterinya tercinta tentang peri hidup dan kehidupan dalam upayanya menggapai pribadi luhur yang diharapkan sesuai dengan ajaran agama.

Naskah ini ditemukan dalam bentuk aslinya di tangan Bapak Parna Mustawa Desa Teruwai Kecamatan Pujut Kabupaten Lombok Tengah. Naskah Prudak Sina tertulis dalam bahasa Sasak Lama, huruf Jejawan sebanyak 56 lempir, kemudian dialihbahasakan ke dalam bahasa Indonesia pada tanggal 15 Maret 2012 s.d 31 Mei 2012 oleh Amaq Irun (52 tahun) dan muridnya Parna Mustawa (45 tahun) dari Desa Teruwai-Pujut dan Amaq Merendah (45 tahun) juga dari Desa Teruwai-Pujut dengan gurunya Bapak Nurasih (55 tahun) dari Desa Kidang-Praya Timur.

Prudak Sina adalah sebuah lakon atau tokoh dalam sebuah cerita yang arif dan bijaksana, baik dalam pikiran, perkataan maupun dalam perbuatannya. Ia adalah lelaki perkasa yang menjadi idaman untuk ditiru oleh para lelaki di muka bumi dan sebagai tempat berlindung bagi kaum hawa. Naskah ini mengandung makna yang sangat dalam dilihat dari segi filsafat ajaran Islam. Oleh karenanya ia sangat jarang muncul untuk dibacakan sebagai suatu penghibur terutama pada acara-acara pesta biasa sebagaimana naskah lontar lainnya. Naskah cerita ini hanya akan muncul untuk ditembangkan dalam acara-acara sakral seperti peringatan hari-hari besar agama, dan hanya terbatas pada orang-orang tua yang gemar mengkaji hakekat agama Islam saja.

Naskah Prudak Sina menceritakan kisah Prudak Sina dalam dialognya dengan isterinya, mengandung sejumlah nilai dan fungsi yang merupakan corak khas masyarakat Sasak dulu, nilai-nilai luhur yang seharusnya menjadi dasar dan panutan bagi setiap suami dalam berpikir, berucap dan berbuat terhadap isterinya. Naskah Prudak Sina sebanyak 200 ayat, terbagi atas empat bagian besar, yaitu Puh Dang-Dang sebanyak 84 ayat (ayat 1-78 dan 179-188), Puh Asmarandane sebanyak 38 ayat (ayat 79-117), Puh Senom sebanyak 36 ayat (ayat 118-145, dan 171-178), dan Puh Pangkur sebanyak 36 ayat (ayat 146-170 dan 189-200).

Masing-masing ayat dan bagian menceritakan kisah yang sama yaitu tentang keimanan kepada Allah swt., bagaimana seharusnya seorang kawula mendekatkan diri atau meleburkan diri ke dalam Zattullah sehingga menjadi sebuah pribadi luhung. Berkaitan dengan hal tersebut, tulisan ini akan menjawab dua permasalahan, yaitu: (1) Bagaimanakah nilai-nilai yang terkandung dalam naskah Prudak Sina dalam kehidupan masyarakat Sasak? dan (2) Bagaimanakah fungsi-fungsi yang tercermin dalam naskah Prudak Sina dalam kaitannya dengan kehidupan masyarakat Sasak? 
Secara teoretis, penelitian ini diharapkan bermanfaat dalam memberikan pandangan dan persepsi positif tentang naskah lama khususnya naskah Prudak Sina, sehingga pembaca khususnya dunia pendidikan dapat menarik manfaat dari padanya. Selain itu, dengan memahami nilai dan fungsi naskah, tulisan ini masuk ke dalam komunitas Sasak tempo dulu dan mau tidak mau atau suka tidak suka akan membandingkannya dengan kondisi masyarakat Sasak masa kini.

\section{METODE PENELITIAN}

Penelitian ini dilaksanakan dengan menggunakan metode deskriptif, yaitu penelitian yang mengutamakan kedalaman penghayatan terhadap interaksi antar konsep yang sedang dikaji secara empiris. ${ }^{2}$ Penelitian kualitatif ini digunakan dengan asumsi bahwa sastra sebagai bahan kajian, merupakan suatu karya kreatif, yang bentuknya senantiasa berubah dan tidak tetap (einmalig), yang harus diberikan interpretasi. $^{3}$

Penelitian ini pun menggunakan pendekatan struktural atau sering dinamakan pendekatan objektif, pendekatan formal, atau pendekatan analitik, bertolak dari asumsi dasar bahwa naskah "Prudak Sina" juga dibentuk oleh berbagai nilai dan fungsi yang membuatnya menjadi sangat bermakna bagi masyarakat Sasak.

Penelitian ini dilaksanakan secara kualitatif, maka keberadaan subjek penelitian tidak memberikan pengaruh terhadap deskripsi parameter penelitian. Sebab makna relevansinya dengan subjek mengacu kepada kuantitas dan bukan kualitas. Sedangkan objek penelitian adalah nilai dan fungsi naskah Prudak Sina dalam masyarakat Sasak karena penelitian ini mengkaji sebuah karya sastra lama, sehingga objek penelitian adalah naskah itu sendiri. Jenis data yang digunakan adalah jenis data kualitatif, yaitu nilai dan fungsi naskah Prudak Sina dalam Masyarakat Sasak. Naskah ini berukuran 24 X 3,5 X $4 \mathrm{~cm}$. Dalam penulisan Takepan khususnya Pujut, tidak dicantumkan pengarang dan tahun terbitnya (Pengarang tidak menonjolkan diri).

Sedangkan sumber datanya adalah sumber data primer, yaitu hasil wawancara langsung dengan para seniman tradisional Pujut, tokoh masyarakat di Desa Teruwai yang terbagi dalam: Penikmat (Sami Kerame/orang yang memiliki hajatan/gawe seperti acara Maulid Nabi Muhammad SAW., selamatan, pesta pernikahan dan lain-lain), $P u$ jangga (penterjemah), Pemaos (pembaca naskah), dan Penyukum (pendukung).

Penelitian ini juga menggunakan metode kepustakaan, dokumentasi, telaah naskah dan wawancara. Metode kepustakaan digunakan pada saat telaah pustaka yaitu dilakukan dengan cara observasi intensif literatur yaitu dengan mencari dan mengumpulkan data-data relevan yang membahas permasalahan ini sehubungan dengan nilai dan fungsi yang terkandung dalam naskah cerita Prudak Sina. Sedangkan, metode dokumentasi digunakan untuk mendapatkan bukti-bukti tertulis yang berkaitan dengan naskah lisan Prudak Sina dan detail penjelasannya. Metode telaah naskah digunakan untuk mendapatkan persepsi yang jelas tentang naskah Prudak Sina, sehingga peneliti dapat memahami bahasa dan makna yang terkandung di dalamnya. Metode wawancara digunakan untuk mendapatkan pengakuan-pengakuan serta 
penjelasan langsung dari nara sumber maupun informan yang berkaitan dengan data penelitian.

Metode deskriptif kualitatif digunakan untuk menguraikan atau menggambarkan serta menjelaskan hasil analisis data teknis secara terperinci. ${ }^{4}$ Permasalahan yang berhubungan dengan nilai-nilai dan fungsi karya sastra fiksi; Prudak Sina, setelah dianalisis kemudian diekspresikan sesuai dengan hasil analisis.

Metode ini digunakan untuk menganalisis atau mengolah data yang terkumpul yang diperoleh selama penelitian. Sedangkan mengolah data adalah usaha kongkrit untuk membuat data itu jelas, sebab seberapa pun besar jumlah dan tingginya nilai data yang terkumpul adalah sebagai hasil pengumpulan data. Sebelum naskah dianalisis dilakukan transliterasi dan terjemahan terlebih dahulu. ${ }^{5}$ Teknik yang digunakan adalah dengan mengklasifikasikan data-data yang diperoleh dan dianalisis dalam bentuk wacana-wacana dan contoh-contoh berdasarkan unsur-unsur yang sedang dikaji. ${ }^{6}$

\section{LANDASAN TEORI}

\section{Perkembangan Pernaskahan di Lombok}

Penelitian awal perubahan dari sifat "keniraksaraan dan keberaksaraan", yaitu dari sifat non tulisan ke tulisan di Lombok masih mengalami hambatan besar. ${ }^{7}$ Pertanyaan mengenai sejak kapan masyarakat Lombok secara pasti mengenal tulisan belum dapat terjawab dengan memuaskan. Bukti-bukti berupa prasasti yang berangka tahun atau naskah-naskah masa lalu yang memuat tahun penulisannya tidak dijumpai. Padahal yang dibutuhkan di sini adalah naskah arktipus, naskah asli yang pertama ditulis. ${ }^{8}$

Menurut sebuah buku yang berjudul "Bunga Rampai Kutipan Naskah Lama dan Aspek Pengetahuannya" Naskah-naskah yang dijumpai lebih banyak berupa salinan atau turunan bahkan naskah tersebut berupa kolofon (petunjuk-petunjuk yang diberikan oleh penulis naskah antara lain berupa: nama penulis, tempat, waktu, yang biasanya terdapat pada penutup naskah. ${ }^{9}$ Kesulitan lebih terasa lagi bila ingin dibuat batas atau fase-fase, sehingga para peneliti terpaksa harus mengambil tanda yang paling dekat dengan jangkauan pandangan dan harus cukup puas untuk memulai dari situ.

Sementara itu, Teew dalam "Sastra dan Masyarakat" mengemukakan bahwa dalam tahapan kebudayaan, dikenal empat tahapan, yaitu: ${ }^{10}$

a. Tahap orality, kelisanan tanpa adanya tulisan.

b. Tahap chirographic, manuskrip, pernaskahan, penemuan tulisan.

c. Tahap typhographic, print culture, percetakan.

d. Tahap media massa modern, audiovisual, secondary orality

Menerapkan empat macam tahapan tersebut untuk menetapkan kurun waktu lintasan sejarah dan tradisi naskah di Lombok, masih memerlukan penelitian yang lebih khusus dan mendalam, serta masih memerlukan banyak sumber asli dan buktibukti otentik. ${ }^{11}$ 


\section{Nilai Naskah Lama dalam Masyarakat Sasak}

Secara umum naskah yang berkembang di Sasak (Lombok) yang ditulis oleh pujangga-pujangga Sasak meliputi dua jenis. Naskah pertama ditulis dalam huruf Jejawan (bentuknya mirip dengan huruf Jawa dan Bali yang terdiri atas 18 huruf: beluq olas). Sedangkan naskah kedua ditulis dengan huruf Jawi (Arab Melayu). ${ }^{12}$

Naskah-naskah yang ditulis dengan huruf Jejawan ada kalanya berbentuk salinan seperti Jatiswara, Dalang Jati, dan Rengganis dan adakalanya berbentuk tulisan (dari cerita oral ke tulisan) seperti Doyan Neda, Cupak Gerantang, dan Lobangkara. Sedangkan yang berbentuk saduran seperti Tapel Adam, Nabi Yusuf, Nabi Ibrahim, Mi'raj Nabi, dan cerita-cerita Menak. Cerita yang disadur dari cerita Menak (Jawa) terdapat dalam berbagai judul diantaranya: Banyurung, Kendit Birayung, Kabar Sundari, Gentur Bumi, Pedang Kemkem, dan banyak lagi yang lainnya. Sedangkan naskah yang berbentuk karangan seperti Silsilah Batu Dendeng, Silsilah Rambitan, Babad Sakra, Babad Praya, Babad Pringgabaya, Babad Selaparang, Pengeling-eling, Mantra dan obat-obatan tradisional. ${ }^{13}$

Sastra lama berupa naskah lontar adalah milik masyarakat yang dibaca dan dinikmati secara bersama-sama. Tradisi membaca naskah sastra lontar di daerah Sasak disebut pepaosan (paos artinya baca). Naskah dibaca dengan cara dilagukan (ditembangkan). Ada enam tembang yang cukup populer di kalangan masyarakat Sasak, yaitu: Durma, Sinom, Smarandana, Pangkur, Dangdang (dangdang Gula), dan Mas Kumambang. Namun demikian pemaos (pembaca) Kitab Serat Menak (Jawa) mengenal pula tembang-tembang seperti Kinanti, Girisa, dan Pucung. Masyarakat suku Bali di Lombok dalam tradisi pepaosannya di samping mengenal jenis tembang-tembang tersebut di atas, juga mengenal tembang "Sekar Agung" yang terdapat dalam naskahnaskah kakawin seperti Kakawin Ramayana, Baharata Yudha, Suta Soma, Arjuna Wiwaha, dan yang lain-lain. ${ }^{14}$

Tradisi pembacaan Hikayat Melayu (Jawi) di Sasak dikenal dengan istilah "bakayat". Naskah yang dibaca adalah hikayat-hikayat seperti Hikayat Nabi-Nabi (Qisasul Anbiya') Qamaruzzaman, Nabi Bercukur, Ali Hanafiah (Yasid) dan lain sebagainya. Pembacaan hikayat ini disertai dengan lagu (istilah Sasak: kayat). Lagu (kayat) Sasak sangat mirip dengan lagu hikayat yang berkembang di Melayu. Pembacaan hikayat ini juga membutuhkan penerjemah dan pendukung. Pembacaan hikayat Melayu dalam bentuk sair disebut "nyair". Kitab syair (bahasa Sasak Saer) yang terkenal antaranya Siti Subaidah, Saer Kubur, dan Qamaruzzaman = kisah Qamaruzzaman dan Saidatul Badun yang tersusun dalam bentuk hikayat (prosa) dan syair.

Tradisi pembacaan naskah yaitu "pepaosan, bakayat, dan saer" merupakan kegiatan yang erat kaitannya dengan upacara adat dan keagamaan. Di samping itu, ada pula naskah yang dibacakan dengan tujuan pengobatan (sympathetic magic). Misalnya Kakawin Selandir (lontar) dibacakan untuk anak yang belum juga bisa berjalan. Indrajaya (lontar) dibacakan untuk anak yang sulit bicara, Indrabangsawan (Jawi) untuk anak yang dungu, dan yang lainnya dimana hal ini kadang hanya berbentuk ke- 
percayaan satu kelompok masyarakat atau komunitas tertentu saja. Kepercaraan semacam ini terutama sekali berkembang pada masyarakat penganut "Waktu-Telu" di masa lalu atau masyarakat Islam "Waktu Lima" masa kini yang masih menyimpan kerohanian lama.

\section{Fungsi Karya Sastra dalam Kehidupan Masyarakat}

Sebagai hasil kesenian lama yang berbentuk tembang dan tertulis, naskah Prudak Sina berkaitan erat dengan kehidupan masyarakat pendukungnya, dan sudah barang tentu memberikan efek kepada kehidupan manusia pendukungnya itu. Hal ini sejalan dengan pendapat Made Sukada bahwa dalam suatu masyarakat, terutama dalam masyarakat yang masih kuat tradisinya, seperti masyarakat suku-suku bangsa di Indonesia, naskah lama, dongeng, cerita dan karya-karya fiksi lainnya memegang peranan penting, di sadari atau tidak. ${ }^{15}$

Cerita seperti Prudak Sina menjadi sangat sakral bagi masyarakat Sasak karena cerita ini tidak dapat ditembangkan secara umum dalam forum masyarakat awam biasa dan untuk keperluan hiburan atau pesta-pesta biasa yang glamour. Begitu sakralnya, cerita ini hanya ditembangkan pada acara-acara khusus seperti pada perayaan hari-hari besar agama dan hanya boleh diperdengarkan kepada orang-orang alim yang gemar mengkaji nilai-nilai agamanya.

Berdasarkan buku Folklor Indonesia, Ilmu Gosip, Dongeng dan Lain-Lain, James Dananjaya berpendapat bahwa fungsi cerita lisan bagi masyarakat Indonesia, Sasak, misalnya, adalah agar pembaca atau penyimak dapat berpikir sebagaimana folknya berpikir. Selain itu, folk juga mengabadikan apa-apa yang dirasakan penting dalam suatu masa oleh folk pendukungnya. ${ }^{16}$

Menyimak pendapat Bascom bahwa fungsi folklor dapat disarikan sebagai berikut: (1) sebagai sistem proyeksi (projective system), yakni sebagai alat pencermin angan-angan suatu kolektif, (2) sebagai alat pengesahan pranata-pranata dalam lembaga-lembaga kebudayaan, (3) sebagai alat pendidikan anak (paedagogical device) dan (4) sebagai alat pemaksa dan pengawas agar norma-norma masyarakat akan selalu dipengaruhi anggota kolektifnya. Berkaitan dengan hal tersebut, Betty Wang juga berpendapat bahwa salah satu fungsi folklor yaitu sebagai protes sosial, dan penyalur pendapat rakyat. ${ }^{17}$

\section{HASIL PENELITIAN}

\section{Nilai Naskah Prudak Sina}

Nilai-nilai yang terkandung dalam naskah Prudak Sina, berdasarkan beberapa nilai utama, yang ada dan relevan serta masih tetap hidup dalam masyarakat Sasak. Dengan demikian, mengingat naskah Prudak Sina ini hanyalah berupa takepan yang berisi dialog antara seorang suami (Ki Prudak Sina) dengan isterinya dan membicarakan tentang ajaran-jaran keagamaan dalam hidup dan kehidupan manusia, maka nilai-nilai utama yang terkandung dalam takepan ini hanya terbatas kepada nilai-nilai pendidikan agama (aqidah, akhlak, dan ubudiyah) dan nilai-nilai pendidikan. ${ }^{18}$ Se- 
dangkan nilai-nilai moral, sudah terkandung di dalam nilai akhlak sebagaimana para ahli memberikan batasan bahwa akhlak itu juga dikatakan Moral. ${ }^{19}$ Dengan demikian, nilai-nilai yang dapat disarikan dari naskah Prudak Sina ini hanyalah nilai-nilai agama dan nilai-nilai pendidikan.

\section{Nilai Agama (Religi)}

Sebagai sebuah naskah lontar dan dibacakan (nembang) pada acara-acara khusus yang bernuansa keagamaan, maka naskah Prudak Sina ini sungguh sarat dengan muatan nilai-nilai keagamaan. Nilai-nilai keagamaan tersebut tercermin dalam tiga kunci pokok keislaman berikut, yaitu: aqidah, akhlaq dan ubudiyah. ${ }^{20}$

\section{Akidah}

Kata aqidah berarti kepercayaan; keyakinan. Aqidah adalah segi teoritis yang dituntut pertama kali dan paling terdahulu dari segala sesuatu untuk dipercaya dengan keimanan yang tidak boleh dicampuri oleh keragu-raguan dan prasangka. Aqidah merupakan masalah yang sangat fundamental dalam kehidupan umat Islam. Ia menjadi tolok ukur nilai hidup dan kehidupan seseorang, karena manusia hidup atas dasar aqidah (kepercayaan dan keyakinan kepada Tuhan). Tinggi rendahnya nilai kepercayaan, memberikan corak kepada kehidupan, atau dengan kata lain, sangat tergantung pada aqidah (kepercayaan) yang melekat-erat dalam hatinya. ${ }^{21}$

Aqidah mengandung unsur-unsur yang sangat kompleks. Termasuk di dalamnya aqidah kepada Tuhan dengan segala sifat-sifatnya, aqidah kepada alam di balik alam semesta ini, yakni kepercayaan kepada adanya alam gaib, aqidah kepada kitabkitab Tuhan, Kepada Rasul-Rasul Tuhan, Aqidah kepada Hari akhir (kiamat) dengan segala peristiwanya, serta aqidah kepada adanya taqdir Tuhan (Qada dan Qadar Tuhan). ${ }^{22}$

Naskah Prudak Sina, dengan bahasanya yang khas betul-betul menitikberatkan pada nilai aqidah ini, agar benar-benar tertanam dalam setiap hati manusia. Sebab dengan demikian, akan menjadi pemacu bagi amalan-amalan atau ibadah-ibadah yang lainnya. Namun demikian, aqidah yang baik dan agung, itu akan dimanifestasikan oleh pendukungnya ke dalam tindakan atau bentuk unsur-unsur keimanan kepada Allah, ${ }^{23}$ setidaknya meliputi:

\section{a. Unsur Ketauhidan}

Ketauhidan adalah suatu kepercayaan (keimanan) yang menegaskan, bahasa hanya Allah yang menciptakan, memberi hukuman, mengatur dan mendidik alam ini (tauhid rububiyah). Sebagai konsekwensi dari keimanan tersebut, maka hanya Allah Zat yang satu-satunya wajib disembah, tempat dimintai petunjuk dan pertolonganNya, serta hanya Dialah zat yang harus ditakuti dan ditaati (Tauhid Uluhiah). Allah adalah Zat yang luhur dari segala-galanya. Dialah hakim yang Maha Tinggi, Yang Tiada Terbatas, dan kekal abadi. Dialah juga Zat yang tiada sekutu sedikit pun dengan alam ini, sumber segala kebaikan dan kebenaran, Maha Adil dan Suci, Mengetahui yang nyata dan yang tersembunyi.

Kepercayaan/keimanan terhadap kekuasaan dan keagungan Allah atas segalagalanya seperti tersebut di atas, banyak ditemui dalam perkataan (monolog dan/atau 
dialog) yang ditampilkan oleh Prudak Sina dan isterinya dalam Naskah Prudak Sina, salah satunya adalah:

(22) Kanging aran ma'ripat puniki, Kaye pundi, Lan tauhid punike, Lan iman paran tegesi, Muah islam puniku, Kadi pundi nyate ni puniki, Tegas ma'ripat punike, Angweruh puniku, Kang sampurne hing pangeran, Tauhid iku, Anunggal langgeng puniki, Ke ane ning pageran \\(Prudak Sina, Pupuh ke 22, Dang Dang).

Terjemahan:

(22) Dan yang bernama makrifat itu, yang mana, dan yang bernama tauhid, lagi mana yangs ebenarnya, juga Islam itu, yang mana kenyataan yangd emikian, yang dimaksud makrifat itu yaitu pengenalan, tentang kesempurnaan Allah SWT, sedangkan tauhid itu, kekal pengenalan tentang ke-Esaan dan keberadaan Pangeran (Allah).

Ayat di atas mengingatkan kepada umat manusia bahwa pengenalan terhadap kesempurnaan Allah swt., itu tercermin dengan adanya tauhid, sedangkan tauhid itu kekal adanya, tidak boleh berubah, tidak boleh menyusut walau sedikit pun. Selain itu, konsep tentang keimanan kepada Allah swt., mengacu kepada keyakinan bahwa Allah itu Maha tinggi dan harus diyakini oleh semua mahluk yang ada di atas bumi ciptaan-Nya ini. Kepercayaan atau keyakinan tersebut, juga tersirat dalam al-Qur'an yang mengatakan: "Katakanlah, Ialah Allah Yang Maha Esa. Allahlah tempat semua makhluk bergantung," (QS 112 : 1-2).

Lebih lanjut, sebagaimana dikemukakan dalam ayat (24) di atas bahwa keyakinan sejati, yaitu hanya pada Allah swt., Allah yang bernama (asma'ul husna). Sesungguhnya Allah ada pada diri, dan hanya dapat dilihat atau dikenal bilamana seseorang memegang teguh tauhid, dan ia akan melihat roh yang sebenar-benarnya, dan bagi mereka yang sudah mencapai tingkat keimanan yang tinggi, maka bagi mereka Allah itu nyata adanya.

\section{b. Unsur Keimanan terhadap Taqdir Allah}

Taqdir atau Qada' dan qadar Tuhan adalah salah satu aqidah yang sangat penting dalam ajaran Islam. Pembahasan tentang taqdir ini, hendaknya didasari oleh iman dan ilmu yang benar, sebab tanpa iman dan ilmu yang benar, seseorang akan tergelincir ke dalam cara hidup yang fatal. Kepercayaan yang benar akan takdir Tuhan ini, akan memberikan sublim (nilai hidup yang tinggi) bagi seseorang, akan menjadi pendorong untuk meraih hidup yang lebih baik dan saleh. Seseorang mempercayai takdir Tuhan dengan benar dan sungguh-sungguh, akan menerima semua keadaan dengan cara wajar dan bijaksana. Baik dan buruk, suka dan duka, hina dan mulia, miskin dan kaya, dan sebagaimnya semua diterima dengan cara yang wajar, karena ia percaya dan yakin, bahwa semua itu telah ditentukan Tuhan semata. ${ }^{24}$

Kepercayaan (keimanan) yang didasari oleh iman dan ilmu yang benar tentang takdir Tuhan ini, banyak kita dapati pada perkataan atau dialog antara tokoh pencerita (Prudak Sina). Kepercayaan dan keyakinan yang tentang ketetapan Allah SWT., dari isi naskah ini, dapat dilihat dalam kutipan berikut: 
(29) Ane dini jaruman ning ati, Keweruhne, Sampurne punike, Jenenging ati tingali, Ujar sekecap iku, Mapan ane jenengi iki, Laku setindak ike, Penerime iku, Tinggal sekedap punike, Maring ilemu, Tegesi ngenep seceret, Nyate ni maring iman \।

(30) Tegesi mengan sekepel iki, Iye Allah, Kang cipte ike, Nyanding skawir tegesi, Penerime iku, Den keweruh sejeruning ati, Iku jati ning egesan, Yen ten uninge iku, Kang aran urip ike, Urip suci, Urip sampurne jati, Dining sampun ma'ripat \।

(31) Nure nane yayi amal niki, Amung siji, Amal ike, Iye sereki lampahi, Garwe nire amuwus, Wecane nie arum manis, Kakang kawule enede, Sakingsih yang agung, Endike keweruhe nike, Dunie aherat, Anuntuning kewelas asih, Wong mude kewelas arse $\backslash \backslash$ (Prudak Sina, Pupuh ke 29 - 31, Dang Dang).

Terjemahannya:

(29) Ada lagi pengenalan di dalam hati, supaya diketahui, kesempurnaannya itu, pandanglah rupamu, pembicaraanmu yang sedikit itulah rupamu ini, laku tindak-tanduk, penerimaan itu, penglihatan dan kedip itu, juga ilmu seperti minum seceret, nyatanya yang dikatakan iman.

(30) Seperti makan segenggam, demikian Allah menciptakan ini, mandu segayung, penerimaan ini, ini perlu diketahui di dalam hati, seperti itu sejatinya hidup, andaikata belum kenal itu, yang dikatakan hidup itu, hidup yang suci, hidup yang sempurna, belumlah dikatakan makrifat.

(31) Percuma dinda hidup berbuat banyak, jasa saja, yang diperbuat, terus dikerjakan, isterinya berbicara, pembicaraannya lemah-lembut, kakang hamba mohon, mudah-mudahan mendapat kemudahan Allah, semoga hamba mengenal yang demikian, di dunia sampai akhirat, mendapat kemurahan dan belas asih, manusia muda hamba ini.

\section{c. Unsur Keadilan Allah}

Unsur aqidah yang lain yang terdapat juga dalam naskah takepan Prudak Sina adalah keadilan Tuhan. Keyakinan terhadap keadilan Tuhan ini hendaknya diukur dengan ukuran yang luas pula, bukan dengan ukuran diri sendiri. Sehubungan dengan hal ini, Hamka berpendapat bahwa: "Keadilan Tuhan jangan hanya diukur dengan ukuran diri sendiri, tidak pula dibawa kepada ukuran yang lebih besar, sebab segala sesuatu akan tampak ketidakadilannya". ${ }^{25}$ Cara mengukur dan memandang keadilan Tuhan dengan cara yang lebih luas seperti tersebut di atas, juga diutarakan dalam naskah takepan Prudak Sina sebagai berikut:

(71) Jroning ucap nure nane kangesti, Kang pangeran Allah kang wus nyate, Kaye ing jrukelebuni, Sipat yang kang luhur, Sing paningalan wus nyate iki, Muah keane ning yang, Iku sun rungu, Hing Allah kewuninge napi ruru, Anging Allah kang keisti, Sirne sedie kang ane \\}

(72) Perluni sahdat puniki, Pteprekare, Hingsun miyarse, Tasdik takli iku reki, Hormati lawan iku, Parbieni sewiji wiji, Tegesi tasdik ike, Netep aken iku, Jroning tuas ajene gembe, Taklim ike, Angaku hing yang widi, Panure nane wikan \\

(73) Hormat tegesi pun malih, Tumulie ken, Hingkang ane ring yang, Tilawat iku tegesi, Ami israh akan iku, Preluni sahdat kekalih, Allah lan Rasulullah, Kang nyate hing 
riku, Hing sahdat kalih kalimah, Enggoni nyate ane ning yang sukseme jati, lawan Nabi Muhammad \\(Prudak Sina, Pupuh ke 72 - 74, Dang Dang).

Terjemahannya:

(72) Heran saya melihat atas yang semua itu, orang yang menjalankan karena banyak yang dikerjakan, tidak mengikuti tasdik, akan Allah Ta'ala dan nabi kaum dan ijmal, karena tidak tunduk hanya mengikuti hawa nafsu, tidak tertib menjalankan, menuruti perjalanan iblis, bid'ah dan suara-suara tidak benar.

(73) Tanyakan asal-usul itu sampai anda paham tentang pikih, paseh, supaya tidak sia-sia, ilmu usul melawan pikih, itu ditanyakan, sampai mengenal diri, orang yang menjalankan agama, dialah yang menjalankan yang lebih bagus, itu yang saya dengar.

(74) Begitu terus tentang makrifat itu, bagi yang sudah mengamalkan yang tinggi adalah para wali, sehingga menjadi agung, bukan menjadi mainan, tidak ada bedanya itu, adanya empat makrifat disalin tembangnya dengan Gunarti Asmarandane.

Data-data di atas menunjukkan betapa dalamnya nilai aqidah (keyakinan) tokoh pencerita tentang keadilan Tuhan dalam menakdirkan peruntungan kepada manusia.

\section{Akhlak (Moral)}

Nilai keagamaan yang lain yang terkandung dalam takepan Prudak Sina adalah akhlak. Akhlak atau sering juga disebut dengan moral diartikan sebagai ajaran baik buruk perbuatan atau kelakuan (akhlak, kewajiban dan sebagainya). Akhlak adalah adat yang dengan sengaja dikehendaki adanya; akhlak adalah azimah (kemauan) yang kuat tentang sesuatu yang dilakukan berulang-ulang sehingga adat (membudaya) yang mengarah kepada kebaikan dan keburukan. ${ }^{26}$ Jadi akhlak mengandung unsur iktiar dan kebebasan, yakni tiada paksaan. Dengan demikian akhlak adalah azimah (kemauan) yang dilaksanakan secara terus-menerus dan berulang-ulang tanpa ada paksaan oleh sesuatu sebab.

Pengertian yang hampir sama diberikan oleh Al-Gazali dalam buku Akhlak Nabi Muhammad SAW, "Akhlak adalah hal ikhwal yang melekat dalam jiwa daripadanya timbul perbuatan dengan mudah tanpa dipikirkan dengan teliti, dan tanpa diperhitungkan terlebih dahulu untung-ruginya, atau dengan tidak menghitung-hitung pahala." 27

Pembicaraan tentang akhlak tidak bisa lepas dari kehidupan seseorang, baik itu orang yang hidup pada zaman dahulu maupun bagi yang hidup dikemudian hari, karena pembicaraan tentang baik dan buruk, benar dan salah itu selalu ada selama manusia itu ada.

Akhlak yang dimiliki manusia ini dapat dikategorikan kedalam dua bahagian besar, yakni akhlak yang terpuji (mahmudah) dan akhlak yang tercela (Mazmumah). Akhlak disebut terpuji manakala menimbulkan perbuatan yang baik lagi terpuji menurut pandangan akal sehat. Sebaliknya, manakala tingkah laku itu menimbulkan 
tingkah laku yang buruk (perbuatan jahat) berdasarkan pertimbangan akal sehat dan sara, maka itu digolongkan akhlak yang tercela (mazmumah). ${ }^{28}$

Beberapa perilaku manusia yang termasuk akhlak mahmudah (terpuji) itu antara lain: berbuat baik diantara sesama manusia, berkata yang benar, ikhlas dan jujur dalam bekerja, tahu kewajiban, dermawan terhadap yang lemah, bersikap berani mempertahankan kebenaran, dan lain-lain kebaikan. Sedangkan perilaku yang tergolong akhlak mazmumah (tercela) itu antara lain: bohong, dusta, kikir, takabbur, riya', dan sebagainya keburukan. ${ }^{29}$

Sebagian dari rumusan perilaku akhlak terpuji dirumuskan dengan jelas oleh pencerita dalam takepan Prudak Sina sebagai berikut:

(6) Atur ingsun ike maring yayi, Enjang lamun, Yayi sun pejah, Endike krame mangki, Den bakti maring kakung, Aje kaye kawule iki, Yugie kang utame, Miwah yen guru, Den ulatne lan kang kelampan, Hing jenengi, Kang tige prekare iki, iku den ulat ne II Kang keruhun pendite kang lami, Kapinduni, Buje kirane, Hing tigeni iku reki, Pendite amar santun, Iye iku pendite radin, Iku peguru aken ne, Yayi dipun antuk, Gruweni mangki angucap, Kados pundi, Pendite kang aran ilemi, Miwah Buje Kirane \I (Prudak Sina, Pupuh ke 6-7, Dang Dang)

Terjemahannya:

(6) Saya katakan kepada adinda, besok jikalau saya telah meninggal adinda, katanya kepada isterinya, supaya berbakti kepada suami, jangan seperti sekarang ini, supaya menjadi manusia utama, kemudian jika mencari guru, terus mencari jangan putus-putus, rupanya yang tiga perkara ini, itu yang dicari, makna yang terkandung.

(7) Yang dicari pertama-tama, dan keduanya, abuje kirana, baru yang ketiganya sekarang, pandite amarsantun, itulah guru yang mursid atau utama itu yang dipertanyakan, supaya adinda memperoleh-nya, isteri sekarang bertanya, bagaimana guru yang berilmu, dan guru yang dikatakan buje kirana?

Pengabdian kepada suami adalah salah satu perilaku yang tergolong akhlakul karimah (akhlak yang mulia). Perilaku untuk mengabdi kepada suami ini merupakan kewajiban bagi setiap isteri selama suaminya masih hidup dan mengayominya, maupun jika sang suami sudah meninggal.

Berbagai cara yang dilakukan oleh manusia agar dapat tetap berbakti kepada suaminya, sebagaimana dikemukakan dalam Prudak Sina berikut ini:

(81) Marme istri lelaki, Amrih nyaking pria, Nure hing dunie bae, Muah reki hing aherat, Pan ambe malicahe, Karene amilih kakung, Alakie pade pisanah \।

(82) Ini pangucap istri, Atakening kakangire, Kakang arabie ingong, Tuan Akrie punape, Lan kakang ngangken sape,Hing pundi kakang ketemu,Hing pundi enggoni kepedak $\backslash$

(83) Yen kakang sari lan mami, Punape endike aras, Atawe kandile reku, Yen kake cekel punape, Den ulih ambe tatanie, Pan kakang panutan ingsun, Pan ingsun Anggawe gurue \\(Prudak Sina, Pupuh ke 81 - 83, Asmarandane). 
Terjemahannya:

(81) Karena isteri dari lelaki bernaung pada pria, bukan hanya di dunia sampai kepada akhirat, saya tidak melecehkan, untuk memilih suami, lelaki yang benar.

Itulah pengucap isterinya bertanya kepada kakaknya, karena kakak suami saya, kakak mengerjakan apa, dan kakak mengaku siapa, di mana kakak bertemu, dan di mana berjumpa.

Andai kata kakang tidur bersama saya, apa yang akan dibicarakan, atau diperbuat, apa yang kakang pegang, itu yang saya tanyakan, karena kakang sebagai panutan, karena saya menjadikan guru.

Bentuk akhlak yang lain yang dikemukakan Prudak Sina, yaitu sikap sabar dan tabah dalam menerima ketentuan Tuhan. Hal ini penting sekali mengingat sikap sabar dan tabah merupakan salah satu perilaku terpuji yang menduduki tempat yang utama dalam menentukan kesempurnaan pribadi. Sabar adalah ibu dari segala akhlak. ${ }^{30}$ Hakekat sabar adalah tahan menerima gangguan dan tahan menderita dari ketidaksenangan orang". 31

Ada beberapa macam sabar yang diwujudkan oleh seseorang antara lain: sabar dalam menjalankan kewajiban terhadap Allah SWT., sabar dalam membela agama dan tanah air, sabar dalam rezki Tuhan, sabar dalam menghadapi segala rintangan, sabar dalam menerima takdir Tuhan, dan sebagainya. ${ }^{32}$

Konsep tentang kesabaran ini dapat dikemukakan dalam ayat-ayat berikut:

(129) Punike kweruh akene, Ring wong sewiji wiji, Aje kurup ane rime, Dining akeh base niki, Tat kasene den jati, Pretingkahani puniku, Muge duluraning yang, Luputing ilat nyambungi, Pundi penampen penerime puniki II (Prudak Sina, Pupuh ke-129, Senom).

Terjemahannya:

(129) Walaupun banyak bahasa yang digunakan, supaya jelas yang sejatinya, sungguh pentingkah yang demikian, mudah-mudahan dikaruniai jauh dari fitnah, bagaimanapun yang datang kepada kita.

Sopan santun adalah juga salah satu bentuk akhlak yang mulia di sisi Allah SWT. Sopan santun dalam hal ini adalah sopan santun yang diwujudkan baik dari berkata, bertindak dan bersikap. Sopan santun ini perlu dimiliki setiap orang, karena kalau sikap sopan santun ini tidak dimiliki, maka seseorang akan kehilangan makna diri di tengah-tengah kehidupan bermasyarakat. Orang yang kurang mengindahkan etika (sopan santun), akan kehilangan kehormatan, bahkan lebih tragis lagi ia akan tersisih dari pergaulan karena dicap kurang ajar, tidak tahu sopan, tidak mengenal etika dan sejenisnya. Sebaliknya, orang yang menjunjung tinggi etika dalam pergaulan, akan dijunjung, dihormati, disegani oleh orang lain yang berada di sekelilingnya. Seseorang akan dikagumi keluhuran budinya jika ia mengenal adat dan etika, sebagaimana dikemukakan dalam beberapa ayat Prudak Sina sebagai berikut:

(130) Aje tekeliru mengkane, Mangke wong sewiji wiji, Den priyatne sire mangki, Pume sire ngati ati, Bener jati aste niriki, Imam ambali temangko, Tingkahi sedekap niki, Luhur kele puniki, Sesorengudal puniku, Mangki den keweruhne, Prekare sedekep iki, Kweruhne den tetep akan punike \। 
(131) Imam sapii rki ike, Den tetep aken ning ati, Imam hanapi lan imam maliki iki, Kang den tetep aken ning budi, Makripat kumpul sapii, Muah wiwitan lan wekasan, Imam sapii ike, Pan den teguh aken sami, Yen sembah yang anut aken sedaye II

(132) Kabeh iman mukmin ike, Sami anuting sapii, Sami medep ing ka'batulah, Wetan ka'bah negare niki, Medep mengidul iki, Lor kabah negare ni iku, Edep mengetan ike, Wetan kabah negare niki, Medep uge menglor ring kabatullah \I

(133) Kidul kabah negare nie, Muah ne pase pre kare niki, Napsu ulamah temangko, Muah napsu amarah iki, Lan napsusawiyah malih, Pan napu mutmainah iku, Yen kang napsu ulamah, Prenahi tingali siriki iki, Rupeni lawang cangkam punike II

(134) Ane dini napsu amarah, Rupe ni abang siriki, Larangi karene temangko, Pernahi hing musuh siriki, Napsu sawiyah tiki, Rupeni ekuningiku, Pernahi ingati temangko, Pernahi sewiji-wiji \\(Prudak Sina, Pupuh ke 130 - 133, Senom)

Terjemahannya:

(130) Janganlah keliru yang demikian pada manusia pribadi-pribadi, janganlah susah, jangan bersedih hati, sebenar-benarnya ajaran itu, Imam Hambali seharang, tingkahnya sedekap kita, di atas pusar kita, di bawah susu kita, supaya diketahui, perkara sedekap itu, ketahuilah supaya tetap yang demikian.

(131) Imam Safi'i sekarang, supaya tetap dilihat, Imam Hanafi, juga supaya tetap di dalam jiwa, kemudian Imam Maliki, tempat berkumpulnya makrifat pada Safi'i. Lalu bibitnya dan bekasnya dan Safi'i manalagi, supaya diketahui yang demikian.

(132) Semua mukmin itu pada mengikuti imam safi'i, semuanya mengahadap ke baitulah, timur,barat, utara, selatan selalu mrnghadap kebaitulah.

(133) Selatan ka'bah, kemudian yg empat perkara itu, nafsu lawwamah, nafsu amarah, nafsu sapiah, nafsu muthmainah, yg namanya nafsu lawwamah tempatnya dapat dilihat pada pembicaraan.

(134) Nafsu amarah rupanya merah, jalanya pada pembicaraan, tempatnya didalam musuh kita, nafsu sopiah rupanya kuning, tempatnya di dalam hati kita masing masing.

\section{Ubudiyah (Ibadah)}

Istilah ubudiyah (ibadah) berarti penyerahan diri. Hal ini melukiskan bahwa Allah SWT merupakan penguasa tertinggi atas manusia sebagai hambanya. Ibadah adalah segala perbuatan manusia sebagai hamba dengan tujuan mendapatkan rahmat, karunia Allah SWT. ${ }^{33}$ Selanjutnya konsep ibadah (ubudiyah) dalam Islam sangatlah luas. Berbicara yang benar atau membicarakan hal-hal yang baik, tidak berbicara kotor, rendah hati, maka yang demikian itu merupakan ibadah, jika seseorang mematuhi hukum-hukum Tuhan, terlebih lagi jika itu timbul dari hati kecilnya yang paling dalam dengan disertai rasa takut terhadap-Nya.

Ibadah yang merupakan pengejawantahan rohaniah itu, banyak mengandung nilai pendidikan yang agung, membawa efek positif bagi yang melaksanakannya maupun bagi orang lain. Ibadah juga merupakan realisasi pernyataan terima kasih hamba kepada Tuhan yang telah menganugerahkan hidup dan kehidupan serta berbagai nikmat dan rakhmat dalam hidupnya. Seseorang yang taat beribadah akan hi- 
dup dalam satu kesatuan masyarakat yang tenteram. Semakin sungguh-sungguh seseorang melaksanakan ibadah maka akan semakin tenteram dan harmonis alur pikirannya.

Pelaksanaan ibadah yang sungguh-sungguh sangat ditekankan dalam naskah takepan Prudak Sina ini, sebagaimana termaktub dalam beberapa ayat berikut:

(83) Yen kakang sari lan mami, Punape endike aras, Atawe kandile reku, Yen kake cekel punape, Den ulih ambe tatanie, Pan kakang panutan ingsun, Pan ingsun Anggawe gurue $\mid 1$

(84) Yen upame skar singgih seane ningsun tukuh ike, Sih paraginepuk mangku, Den teke kangsun tingal ire, Lan sipat ingkang mulie, Sukseme ningsun karep iku, Amanggih hing rahamatullah $\backslash 1$

(85) Lan sun gawi pare singgih, Kenyate yan sih ike, Lan para sun angken reku, Dedalani punike, Lan punape kerasente, Puniku pumanggih ingsun, Angweuh ing krame II

(86) Kang istri amuwus malih, Wanten kari atur ambe, Samsalah cipte mangku, Ambat nie ring tuan, Pan sampun ning mengkane, Asari kalawan ingsun, Ajinah kalawan sire II (Prudak Sina, Pupuh ke 83 - 86, Asmarandane).

Terjemahannya:

(83) Misalkan saya nakzis, bagaimana cara memandikan dan bagaimana tuan mandi, saya ikut mandi, supaya menjadi ujud tunggal, karena tidak ada ujud, tetapi ada sisa sejati.

(84) Sebab mandi itu, karena mandi itu membersihkan akan zahir, yang bernama johar itu, air suci-mensucikan, dinding bumi itu, demikianlah seharusnya, supaya menjadi bersih.

(85) Dan lagi yang dinamakan junub atau jinabah itu, berapa banyak perkara, agar supaya mukaranah, yang wajib pada jinabad, berapa banyaknya supaya saya mengetahui.

(86) Perlu junub itu, ada tiga perkara, air yang mengalir, dan suci yang kedua adalah sahadat dan yang ketiganya meratakan air itu, supaya basah seluruh badan.

Nilai ibadah yang lain yang terkandung dalam takepan Prudak Sina ini adalah sebagai berikut:

(107) Kaye te iman reki iki, Yen milu maring jro nale, Hing dalam iman pinendemi, Yate sasar pemanggih nie, Yen tan ane punike, Yakti sasar susur iku, Hing langkung tur kilangan \\

(108) Yen mengkane ame niki, Tane name anggawe iman, Bide lamun urip reku, Pasti ane umah niki, Hing dalam urip niki, Ane hing lidah enggenipun, Jantung punget sisimpenan $\backslash 1$

(109) Lamun ning johar puniki, Peteng prekare akeh niki, Maring cangkemku reku, Kaping tige ne te muah, Hing jro dade lungguhe, Kaping empat iku, Ane ing jro ati sucie II

(110) Yen mang kono iman niki, Yakti suwung pemanggih nie, Tanane karieni reku, Kang aran iman punike, Pasti ning imanike, Tan ane damari iku, Pasti jim tanpe sware \। (Prudak Sina, Pupuh ke 107 - 110, Asmarandane). 
Terjemahannya:

(107) Yang bernama Imam Safi'i, berhadapan dengan kak baitullah, Imam Hanafi, Imam Maliki, Imam Hambali, semuanya pada tafakur ke kakbaitullah.

(108) Kemudian lagi yang dimaksud manusia mukmin, mengerjakan salat lima waktu, menghadap kak baitullah, tidak menyimpang daripada itu, nikmat bersama Allah SWT, di dalam baitul muqadast, terus menyembah.

(109) Yang dimaksud ka'bah itu, ada di dalam jisim adanya, sejatinya johar itu, di dalam jabal jisim, ada di dalam jisim itu, jisim latif di dalam latif, jiwa di dalam jiwa.

(110) Yang bernama niat sejati, nawaitu usalli, ripaal adatsil, baitul itu sembahnya, karena lapal itu, ibaratnya menjadi lapalmu, nawaitu usalli.

\section{Nilai Pendidikan (Educational)}

Nilai pendidikan yang dimaksudkan dalam tulisan ini adalah cermin, teladan kehidupan, perasaan dan sikap penilaian dan ajaran-ajaran yang mengacu kepada pembentukan karakter manusia dari tidak tahu menjadi tahu atas sesuatu. ${ }^{34}$

Naskah Takepan Prudak Sina sebagai sebuah karya sastra mengandung nilai-nilai pendidikan dan keteladanan yang dicontohkan oleh tokoh pencerita (Prudak Sina) yang dapat diteladani oleh para pembaca khususnya ketika ia mengajarkan kepada isterinya akan makna hidup dan kehidupan serta pokok-pokok ajaran Agama Islam yang benar menurut sunah Nabi Muhammad SAW.

(4) Tur ike wong luhung reki hiki, Sayekti ni, Pume iling ing ujar, Ingsun iki tuturi, Aje sire yayi iku, Sire yayi ajeku mami, Dining durung tumeke, Jatini pengeweruh, Prayogye takonane, Ari ning wang tingalne ing urip, Iku peguru aken ne \।

(5) Rabinire mangki angling aris, Hinggih nuhun, Ring sepengendike, Muge den tulus asihi, Saking tambuh maring ingsun, Sape sire kang medangi, Yen teke sandingne, Etuduh marge ayu, Ki Perudaksine angucap, Pire bare, Yen ane asih iyang widi, Asung weruhi sire \\(Prudak Sina, Pupuh ke 4 -5, Dang Dang).

Terjemahannya:

(4) Manusia yang tidak dapat digoda adalah manusia luhung (bersih), sebaiknya kamu dengar apa yang dikatakan, aku sekarang akan ceritakan, jangan sekalikali kamu aduhai kekasihku, apabila kamu ketemu, sebenar-benarnya tahu, sebaiknya bertanyalah atau tanyakanlah hal ini, aduhai kekasihku, lihatlah hidupmu, itulah yang perlu ditanyakan.

(5) Sambil menyembah, isterinya sekarang berbicara halus, ya, Kakang, saya akan mendengar apa yang Kakang katakan, mudah-mudahan saya dapat diterima, siapa yang memberikan penerangan, jika dia datang, yang memberikan pengajaran bagus, Prudak Sina berbicara, berapa banyak cara, untuk mengenal Tuhan, saya akan mengerti melalui anda.

Ki Prudak Sina dengan penuh kesabaran dan ketekunan serta dilandasi dengan perasaan cinta kasih memberikan wejangan dan keteladanan kepada isterinya dalam sepanjang kisah. Alur tanya jawab (dialog) yang harmonis memberikan sebuah indikasi kuat bahwa pola mendidik yang diajarkan cukup mumpuni untuk dicontohi 
dan diteladani oleh para pembaca (pendengar) kisah. Bagaimana selayaknya seorang suami mendidik dan memberi paham kepada isterinya tentang hal-hal yang baik, khususnya tentang nilai-nilai keagamaan. Beberapa contoh berikut ini, memberikan gambaran yang jelas tentang makna pendidikan yang terkandung dalam kisah Prudak Sina.

(7) Kang keruhun pendite kang lami, Kapinduni, Buje kirane, Hing tigeni iku reki, Pendite amar santun, Iye iku pendite radin, Iku peguru aken ne, Yayi dipun antuk, Gruweni mangki angucap, Kados pundi, Pendite kang aran ilemi, Miwah Buje Kirane \I

(8) Mirah pendite amar santun puniki, Padangene, Kawule miyarse, Prudaksine ujari, Pendite ilemi iku, Penu sareh wuwus sariki, Anurun sudi kariye, Sewuwus rahayu, Aje tebalas tariye, Sebeneri, Iku den gurunen mas yayi, Setuhu ning pendite \।

(9) Kang pendite amar santun puniki, Ping twasi, Muliye kang sesire, Ngebek king jagat pujini, Se wus iki puniku, Apan iku puji ngembakti, Angandal guru nire, Dadi puji nipun, Tkeng rimeni selembar, Kelebut agi, Tan simpang dadi pemuji, iku pendite mulye ||

(10) Pendite buje kirane iki, Datan pegat, Deniye amanguntape, Amedangi serire iki, Anyegah napsu nipun, Nure pegat amanganne sami, Sejati ni wus nyate, Tan ane kang kedulu, Sampun ni weluye padang, Pangestuni, Tan ane kawule gusti, Wus kareming setulah $\backslash 1$

(11) Iku aje dipun guruni, Sang pendite, Yayi kang mengkane, Kelime prekare reki, Pendite sipat iku, Tanpe lapal kaping kalih, Kaping tige mare kecance, Ping sekawan iku aganten umus punike, Ping lime ni, Ketawe brane wastiki, Iku sun miyarse II (Prudak Sina, Pupuh ke 7-11, Dang Dang).

Terjemahannya:

(7) Yang dicari pertama-tama, dan keduanya, abuje kirana, baru yang ketiganya sekarang, pandite amarsantun, itulah guru yang mursid atau utama itu yang dipertanyakan, supaya adinda memperoleh-nya, isteri sekarang bertanya, bagaimana guru yang berilmu, dan guru yang dikatakan buje kirana?

(8) Kemudian guru yang amar santun, beritahulah, saya akan mendengarnya, Prudak Sina memberitakan pendita alami itu, paseh dalam berbicara, benar dalam perbuatan, baik sesudahnya, tidak pamrih, sebenarnya, itulah guru yang dinda cari, guru yang sebenar-benarnya.

(9) Kang pandita amar santun itu, perbuatannya, mulia seluruh tubuhnya, pujinya memenuhi jagad raya, sesal itu, semua itu puji bakti, ngandal guru nire, jadi pujinya sampai ujung rambutnya, masuk di dalamnya, tidak ada yang menyimpang, semua jadi pujinya, itu pendita yang mulia.

(10) Pandita buje kirane itu tidak putus-putus selalu bertapa, memandang dirinya, mencegah hawa nafsunya, tidak henti-hentinya memandang dirinya, sebenarbenarnya sudah nyata, tidak ada yang dia lihat, seluruhnya memenuhi alam, pengetahuannya tidak ada kecuali Gusti (Allah) sudah karam tenggelam ke Zatullah. 
(11) Sekarang yang tidak perlu digurui, sang guru yang tidak memegang lima perkara ini, guru yang tidak mengikuti sifat, yang kedua tidak punya lafal, yang ketiga merak bencana, yang keempat mengganti atau membuat-buat hukum, dan kelimanya kesawa buan wastiki, itu yang saya dengar.

\section{Fungsi Naskah Prudak Sina}

Sebagaimana telah dikemukakan pada pembahasan terdahulu, bahwa fungsi naskah Prudak Sina sebagaimana naskah lama pada umumnya dapat disarikan sebagai berikut: 35

1. Sebagai sistem proyeksi (projective system), yakni sebagai alat pencermin anganangan suatu kolektif. Fungsi naskah lama Prudak Sina yang berperan sebagai sistem proyeksi atau sebagai alat pencermin angan-angan suatu kelompok masyarakat pada saat itu, tidak ditemukan secara jelas, karena tidak satu pun dari isi naskah yang secara khusus membicarakan tentang peradaban sebuah kelompok komunitas (Sasaka) dan semata-mata berbicara tentang bagaimana mendekatkan diri dengan al-Khalik.

2. Sebagai alat pengesahan pranata-pranata dalam lembaga-lembaga kebudayaan. Fungsi naskah Prudak Sina yang dianggap sebagai alat pengesahan pranata-pranata dalam lembaga-lembaga kebudayaan pun tidak ditemukan dalam naskah lama ini.

3. Sebagai alat pendidikan anak (paedagogical device). Naskah Prudak Sina mengandung nilai-nilai pendidikan yang teramat halus dan dalam, sebagaimana cara penutur (Ki Prudak Sina) menceritakan atau menulis kitab tersebut. Dari dialog yang disampaikan antara Ki Prudak Sina dengan isterinya, ditemukan makna atau cara mendidik isteri yang sangat arif dan bijaksana. Hal tersebut merupakan fungsi utama dari pada naskah lama ini. Fungsi pendidikan lain, yaitu bagaimana seorang Ki Prudak Sina berupaya memberikan pengetahuan tentang ketaatan dan tauhid kepada para komunitas di tempat itu kepada Allah SWT. Fungsi utama dari naskah ini dimaksudkan agar memberikan pengajaran sekaligus pendidikan kepada pendengarnya tentang keimanan dan ketaqwaan kepada Allah SWT. Untuk keperluan itu, penembang atau pemaos dalam hal ini akan berfungsi sebagai seorang guru yang mana dari mulutnya akan keluar petuah-petuah atau nasehat-nasehat dari Ki Prudak Sina tentang keimanan kepada Allah SWT. Dengan demikian, fungsi utama dari naskah ini yaitu sebagai sarana penyebaran Agama Islam, atau sebagai sarana siar atau dakwah agama yang disampaikan melalui tembang.

4. Sebagai alat pemaksa dan pengawas agar norma-norma masyarakat akan selalu dipengaruhi anggota kolektifnya. Fungsi ini pun tidak ditemukan dalam naskah Prudak Sina ini. Dengan demikian, fungsi naskah Prudak Sina sebagai sebuah naskah lama hanyalah sebagai alat untuk menyebarkan atau mendakwahkan agama Islam dari seorang guru yang amar santun (Ki Prudak Sina) kepada orang lain, dan orang yang paling dekat adalah isterinya. Dalam hal ini sejalan dengan perintah dakwah, bahwa hendaklah diberikan pelajaran kepada anak dan isteri. 


\section{SIMPULAN}

Naskah Lontar "Prudak Sina" terdiri atas 200 ayat, memang terbagi atas empat bahagian besar yaitu: Puh Dang-Dang, Puh Asmarandane, Puh Senom dan Puh Pangkur. Namun keempat bagian itu sambung menyambung alur ceritanya.

Sedangkan nilai dan fungsi yang terkandung dalam naskah lontar ini adalah sebagai berikut:

1. Nilai yang terkandung yaitu nilai religiusitas (aqidah, akhlak, kasih sayang dan kesetiaan dan ubudiyah)

2. Fungsi yang terkandung yaitu fungsi penyiaran Agama Islam, yaitu Ki Prudak Sina berupaya untuk mendakwahkan syiar-syiar Islam melalui tembang yang mengandung pengetahuan tentang konsep keimanan kepada Allah SWT.

Dilihat dari keberadaan naskah-naskah lama, khususnya naskah Prudak Sina memiliki nilai-nilai tinggi serta fungsi-fungsi yang cukup bagus untuk dipelajari. Dari aspek-aspek tersebut apabila ditinjau dari segi urgensinya, maka di satu pihak ada nilai-nilai yang masih relevan untuk diterapkan dan dikembangkan pada masa kini. Untuk itu disarankan agar tetap melestarikan dan mempelajari naskah-naskah lama tersebut, dan mengambil pelajaran darinya.

\section{CATATAN AKHIR}

1. James Dananjaya, Folklor Indonesia, Ilmu Gosip, Dongeng dan lain-lain, Cet. IV, Jakarta: Pustaka Utama Grafiti, 2004.

2. Saminto Sayuti, Dasar-dasar Analisis Fiksi, Yogyakarta : LP3ES, 2008.

3. Made Sukada, Beberapa Aspek Tentang Sastra Denpasar: Penerbit Kayumas \& Yayasan Ilmu dan Seni Lasiba Denpasar, 2007.

4. Mangunwijaya, Sastra dan Religiusitas, Yogyakarta: Gajahmada University Press, 2012.

5. Soeparman Natawidjaya, Pengantar Apresiasi Sastra dan Budaya, Jakarta: PT. Inter Masa, 2012.

6. A. Teeuw, Membaca dan Menilai Sastra, Jakarta: PT. Gramedia, 1991.

7. Lalu Wacana, dkk., Sejarah Nusa Tenggara Barat, Jakarta, Depdikbud, 1988.

8. Lalu Wacana, Sejarah Perkembangan Kesusasteraan Sasak, Makalah pada Penataran Pernaskahan di NTB, 1989.

9. Depdikbud NTB, Bunga Rampai Kutipan Naskah Lama dan Aspek Pengetahuannya, Dirjen Kebudayaan Museum NTB, 1990.

10. A. Teeuw, Sastra dan Masyarakat, Makalah pada Penataran Pernaskahan di NTB, 1989.

11. Depdikbud NTB, op. cit.

12. Y.S. Achdiati, Peradaban Manusia Zaman Mataram Kuna, Jakarta: Gita Karya, Tanpa Tahun Penerbitan.

13. Lalu Wacana, Sejarah Perkembangan Kesusasteraan Sasak, op. cit.

14. Y.S. Achdiati, op. cit.

15. Made Sukada, op. cit.

16. James Dananjaya, op. cit.

17. Ibid.

18. Soeparman Natawidjaya, op. cit.

19. Hamka, Falsafah Hidup, Jakarta: Bulan Bintang, 1972. 
20. Hamka, Pribadi, Jakarta: Bulan Bintang, 1982.

21. Zakiah Daradjat, Dasar-Dasar Agama Islam, Buku Pegangan Agama Islam Pada Perguruan Tinggi Umum, Proyek pembinaan Pendidikan Agama Islam pada Perguruan Tinggi, 1984.

22. Ahmad Muhammad Al-Hufy, Akhlak Nabi Muhammad SAW., Jakarta: Bulan Bintang, 2008.

23. Abul A'la Al-Maududi, Dasar-Dasar Aqidah Islam, Jakarta: Media Da'wah, 2006.

24. Hamka, Pribadi, Jakarta: Bulan Bintang, 1982.

25. Hamka, Falsafah Hidup, op. cit.

26. Ahmad Muhammad Al-Hufy, op. cit.

27. Ibid.

28. Abul A'la Al-Maududi, op. cit.

29. Zakiah Daradjat, op. cit.

30. Hamka, op. cit.

31. Ahmad Muhammad Al-Hufy, op. cit.

32. Ibid.

33. Abul A'la Al-Maududi, op. cit.

34. Soeparman Natawidjaya, op. cit.

35. Soetarno, Peristiwa Sastra Indonesia, Surakarta: PT. Widya Duta, 1966.

\section{DAFTAR PUSTAKA}

Achdiati, Y.S. Peradaban Manusia Zaman Mataram Kuna. Jakarta: Gita Karya, Tanpa Tahun Penerbitan.

Dananjaya, James, Folklor Indonesia. Ilmu Gosip, Dongeng dan Lain-lain. Cet. IV, Jakarta: Pustaka Utama Grafiti, 2004.

Daradjat, Zakiah. Dasar-dasar Agama Islam, Buku Pegangan Agama Islam Pada Perguruan Tinggi Umum. Proyek pembinaan Pendidikan Agama Islam pada Perguruan Tinggi, 1984.

Depdikbud NTB. Bunga Rampai Kutipan Naskah Lama dan Aspek Pengetahuannya. Dirjen Kebudayaan Museum NTB, 1990.

Hamka. Falsafah Hidup. Jakarta: Bulan Bintang, 1972.

Hamka. Pribadi. Jakarta: Bulan Bintang, 1982.

al-Hufy, Ahmad Muhammad. Akhlak Nabi Muhammad saw. Jakarta: Bulan Bintang, 2008.

Mangunwijaya. Sastra dan Religiusitas. Yogyakarta: Gajahmada University Press, 2012.

al-Maududi, Abul A'la. Dasar-dasar Aqidah Islam. Jakarta: Media Da'wah, 2006.

Natawidjaya, Soeparman. Pengantar Apresiasi Sastra dan Budaya. Jakarta: PT. Inter Masa, 2012.

Sayuti, Saminto. Dasar-dasar Analisis Fiksi. Yogyakarta: LP3ES, 2008.

Soetarno. Peristiwa Sastra Indonesia. Surakarta: PT. Widya Duta, 1966.

Sukada, Made. Beberapa Aspek tentang Sastra. Denpasar Bali: Penerbit Kayumas \& Yayasan Ilmu dan Seni Lasiba Denpasar, 2007.

Teeuw, A. "Sastra dan Masyarakat." Makalah. Dipresentasikan pada Penataran Pernaskahan di NTB, 1989.

Teeuw, A. Membaca dan Menilai Sastra. Jakarta: PT. Gramedia, 1991.

Wacana, Lalu dkk. Sejarah Nusa Tenggara Barat. Jakarta: Depdikbud, 1988.

Wacana, Lalu. "Sejarah Perkembangan Kesusasteraan Sasak," Makalah. Dipresentasikan pada Penataran Pernaskahan di NTB, 1989. 